\title{
Pap Utilization Survey in Nueva Vida, Nicaragua: Professional and Health Promotoras Partnership
}

\author{
Olushola O. Ogunleye \\ Liberty University \\ Bethesda J. O'Connell \\ Liberty University \\ Megan A. Quinn \\ East Tennessee State University \\ Lea C. Florence \\ East Tennessee State University \\ Kaitlyn Shirely \\ East Tennessee State University
}

Cervical cancer is the second most common cancer affecting women in developing countries and accounted for $84 \%$ of the global incidence of cervical cancer in 2012. Nicaragua is one country illustrating this disparity, with an annual cervical cancer mortality six times the U.S. rate. This may be explained by lack and poor utilization of effective screening programs, especially the Papanicolaou, or Pap, smear. This study resulted from a partnership formed by faculty and students from two U.S. universities and a Nicaraguan nonprofit organization to conduct projects to benefit a community in Nicaragua. To promote a free Pap smear program provided by the local clinic, a community-wide survey regarding Pap smear utilization was conducted with local health promotoras (promoters). Of 1,117 women, $78.4 \%$ reported ever having a Pap smear, of whom 11.1\% had not received their results, while results were reported as normal by $78.9 \%$, and abnormal by $10 \%$. The most common reasons for not having a Pap smear were refusal to test, fear, and pain. Proportions of women who ever had a Pap smear varied by etapa (stage/neighborhood, $p<.001$ ). Findings are useful for policy development to improve the clinic's screening services and encourage full utilization of Pap smears.

Keywords: Nicaragua, Pap smear, screening, utilization, cervical cancer, health promotoras

The contribution of the local clinic and community health promotoras was vital to this project as well as to the community's well-being. 


\section{Introduction}

With approximately 530,000 cases and 270,000 deaths occurring in 2012, cervical cancer is the fourth most common cancer in women worldwide (World Health Organization [WHO], 2017). Though the worldwide prevalence of cervical cancer is currently declining, significant disparities exist between developed and developing countries, with an increase in the total number of cases projected to occur in the next few decades (Murillo, Herrero, Sierra, \& Forman, 2016). In developing countries, it is the second most common cancer among women, with an estimated 445,000 new cases in 2012 (84\% of the global incidence; WHO, 2016). As many as 10 to 35 per 100,000 women die due to cervical cancer in developing countries, compared with two to four deaths per 100,000 in developed countries (Olesen, Butterworth, Jacomb, \& Tait, 2012).

There are two major approaches used for the prevention and control of cervical cancer: secondary prevention via cytology and/or human papillomavirus (HPV) tests to screen for precursor lesions of cervical cancer, to be followed, when indicated, by colposcopy and treatment; and HPV vaccination for primary prevention (Bosch et al., 2016). Secondary prevention via screening is especially relevant for cervical cancer, as it is the only reproductive tract malignancy that is preventable via identification of its precancerous lesions and subsequent treatment (Gharoro \& Ikeanyi, 2006). How to combine these approaches in effective intervention programs is an issue that is yet to be determined in many developing countries that are already grappling with the cost of such programs (Colantonio et al., 2009).

The most widely practiced screening approach for cervical cancer involves cervical cytologic testing (the Papanicolaou, or Pap smear). Many precancerous lesions in asymptomatic women can be detected early and receive treatment, thereby halting progression to cervical cancer and saving many lives (Olesen et al., 2012). By current recommendations, screening is not advised for women younger than 21 years, or for women older than 65 years who previously had adequate screening and whose risk has not increased (Bychkovsky et al., 2015). In 82\% of countries, cervical cancer is among the three most common cancers occurring in females under 45 years old, thus attesting to its early age of onset (Bosch et al., 2016).

Pap smear screening is effective in reducing the incidence of invasive cervical cancer, decreasing the occurrence of late-stage disease, and saving lives (Bychkovsky et al., 2015). Countries whose Pap smear screening covers $50-69 \%$ of women every $3-5$ years have an annual cervical cancer death rate of four per 100,000 women, while the rate is two or fewer per 100,000 women in countries whose coverage is above $70 \%$ (Bosch et al., 2016). By using an effective screening service in the last 4 decades-a consequence of the introduction of the Pap test in 1941—the United States has reduced its incidence of cervical cancer by $70 \%$. However, women who have never been screened with a Pap smear account for $29-50 \%$ of all cervical cancer diagnoses despite access to healthcare in developed countries (Ogunwale et al., 2016).

A major barrier to cervical cancer screening is the cost of the procedure. The low cervical cancer morbidity and mortality in developed countries is often attributed to the existence and affordability of effective national screening programs that detect precancerous lesions and allow for successful treatment. In contrast, the lack of these services in developing countries and, in many cases, the poor utilization, unaffordability and inefficiency of the services where they do exist, account for the greater burden of the disease in developing countries (Murillo et al., 2016; Olesen et al., 2012). 
Ensuring wide Pap smear screening coverage and providing the necessary facilities for diagnosis and treatment of precursor lesions in women who screen positive require substantial financial investments, which many developing countries cannot afford (Bosch et al., 2016).

Additional factors limiting utilization of Pap smears are the fears women often have arising from reports of adverse effects of the procedure, and costs of overdiagnosis and overtreatment of certain cervical neoplasms that are very unlikely to advance to cancer (Bosch et al., 2016). Reports of obstetric complications in young women following surgical treatment of cervical lesions, though rare, including increased frequencies of preterm births and global perinatal mortality, are other factors that increase these fears (Bosch et al., 2016).

Perceived benefits and factors encouraging utilization of Pap smears include women's perception of being in control of their health and peace of mind (Agurto, Bishop, Sanchez, Betancourt, \& Robles, 2004), being wealthy and having a recent doctor's visit (Soneji \& Fukui, 2013), incorporating Pap smears with routine antenatal screening (Hyacinth, Adekeye, Ibeh, \& Osoba, 2012), and targeting interventions for women who have clear risk factors (Olesen et al., 2012).

Detection of HPV is directly proportional to the grade of the cervical lesion (Hindryckx et al., 2006). It is estimated that HPV vaccination of adolescent girls, with an efficacy of $93 \%$ to $100 \%$, could prevent up to 70\% of cervical cancer cases (Ciapponi, Bardach, Glujovsky, Gibbons, \& Picconi, 2011; Murillo, Molano, Martinez, Mejia, \& Gamboa, 2009; Pan American Health Organization [PAHO], 2014). HPV vaccination, when combined with cervical cancer screening, is regarded as one of the most cost-effective interventions for prevention and control of cervical cancer, especially in developing countries where Pap smear and other cytology-based screening techniques have not been fully implemented or utilized (Colantonio et al., 2009; Franco et al., 2008; Murillo et al., 2009). However, access to HPV vaccination in these countries is often limited by cost and the lack of infrastructure to maintain cold chain and safe storage of the vaccines (Saxenian, 2007).

Recognizing that low-resource settings may have difficulty in implementing effective cervical cancer screening programs, the American Society of Clinical Oncology released a set of new global cervical cancer screening guidelines in 2016 . The purpose of these guidelines was to help countries use the resources they have available to implement the most effective cervical cancer screening policies they can afford (Printz, 2017). Therefore, countries are expected to have cervical cancer screening guidelines that are commensurate with their resource level. Through these guidelines, countries/settings that are classified as having limited resources need only to screen women aged 30 to 49 years every 10 years, while those classified as having basic resources will only need to screen women one to three times in their lifetime while they are in the 30- to 49-year-old age group (Printz, 2017).

Where resources allow, the preferred method for cervical cancer screening, as recommended by the new American Society of Clinical Oncology guidelines, is HPV testing, usually done together with Pap smear screening. However, because this may not be feasible in low-resource settings, visual inspection of the cervix with acetic acid (VIA) is now accepted as an option that has almost equal sensitivity and specificity as conventional cytology (Murillo et al., 2010; Printz, 2017). PAHO (2014) promotes "see-and-treat" as a cost-effective means of reducing cervical cancer incidence. VIA has been shown in recent studies to be an inexpensive, non-invasive, alternative screening technique for cervical cancer (WHO, 2012). In addition, it does not require sophisticated skills to perform; it can be 
done by well-trained community health workers in a local health center. Other advantages it provides are quick access to test results so that women who require further evaluation and treatment of precancerous lesions can receive them on the same day or be referred immediately to facilities where those services are available (WHO, 2012). This "see-and-treat" approach has the potential to reduce loss to follow-up and ensure treatment adherence.

In Latin America, cervical cancer has an estimated annual incidence of 21.2 per 100,000 women and an annual mortality rate of approximately 8.7 deaths per 100,000 women; as in the rest of the developing world, it is the second most frequent cause of cancer-related mortality among women (Bychkovsky et al., 2015; Moore et al., 2014; PAHO, 2014). When standardized by age, the incidence of cervical cancer among women in Latin America is 29.2 per 100,000, while the mortality is 13.6 per 100,000 (Murillo et al., 2008). Cervical cancer mortality is approximately three times as high in Latin America and the Caribbean than in North America, further revealing existing health disparities. In 2009, cervical cancer killed 19.4 women per 100,000 in Nicaragua, a rate six times that of the United States (Arossi, Sankaranarayanan, \& Parkin, 2003), such that cervical cancer is ranked as the most common cancer among women in Nicaragua (PAHO, 2013). Studies of cervical cancer trends in Latin America spanning 1960 to 1993 report that mortality due to cervical cancer has had no significant downward change, but has rather increased (Institut Catala d'Oncologia HPV Information Center, 2016). It is also projected that by 2030, mortality due to cervical cancer will increase by up to $45 \%$ (Bychkovsky et al., 2015; PAHO, 2014). The high frequency of risk factors for cervical cancer and the low Pap smear screening coverage in Latin America have been postulated as major determinants of the high incidence and mortality rates of cervical cancer (Colantonio et al., 2009).

Pap smear utilization rates vary widely in developing countries. Analysis of Demographic and Health Survey data from 1987 to 2008 for several Latin American countries found that the proportion of women with a recent Pap smear in all the countries was less than 55\% (Soneji \& Fukui, 2013). A population-based survey in Rivas, Nicaragua, reported that only $41.1 \%$ of women who had been sexually active at least 3 years had received a Pap smear within that period (Claeys et al., 2002). In a similar survey of women aged 18-65 years in Nigeria, while $50.9 \%$ of the women were aware of cervical cancer and $38.6 \%$ of them were aware of Pap smear screening, only $10.2 \%$ of them had ever had a Pap smear (Hyacinth et al., 2012). Although Pap smear screening was adopted in Latin American countries since the early 1960s, several of which have attempted to implement national cervical screening programs, coverage is still poor in these countries. Thus, they have been unable to significantly reduce the burden of cervical cancer (Murillo et al., 2008).

When reproductive, maternal, and/or child health programs utilize interventions that are participatory and community-based, they produce sustainable health outcomes that are both preventive and curative (Decat et al, 2013; Gilmore \& McAuliffe, 2013; Oguro \& Horiuchi, 2016). Such interventions often involve community health workers. Health promotoras-as community health workers in Nicaragua and other Latin American countries are called-are highly motivated community members trained to use public health principles to promote adoption of good health behaviors and address the health needs in their communities (McDermott-Levy \& Weatherbie, 2012). Interventions implemented through partnership with promotoras have been shown to significantly increase health literacy and cervical cancer screening among Hispanic/Latino women in the United States (O’Brien, Halbert, Bixby, Pimentel, \& Shea, 2010) and in rural Mexico (Elliot, Belinson, Ottolenghi, Smyth, \& Belinson, 2013). Similarly, cancer-screening behaviors were 
improved for breast cancer and cervical cancer among Korean American women in health literacy interventions led by community health workers (Han et al., 2017).

The purpose of this study was to assess, through a partnership between public health practitioners and health promotoras, the utilization of and barriers to cervical cancer screening in Nueva Vida, Nicaragua. In addition, it aimed to obtain information on the population served that was not otherwise available, as well as preliminary data for grant applications to expand the clinic's program.

\section{Methods}

\section{Background}

Nueva Vida, literally translated as "new life," is a town located just outside of Ciudad Sandino, Nicaragua. Its development resulted from movements out of the major cities of Nicaragua by people seeking refuge following earthquakes and other natural disasters (S. Woodard, personal communication, July 9, 2014). Hurricane Mitch, which devastated much of Central America in 1998, was a significant factor that led to the creation of Nueva Vida. Nueva Vida expanded further following other natural disasters. Because few people ever leave to return to their original residences, Nueva Vida has grown in size and numbers over time. The town is organized in unofficial settlements, called etapas, which means "stages" in the local Spanish language, based on the rate at which settlement camps of people who relocated to the community were formed, Etapa 1 being the oldest and Etapa 5 being the most recent. There are surrounding rural areas that were incorporated into Nueva Vida as it expanded; these include Trinidad Central, Trinidad Norte, and Cuajachillo. Living conditions and socioeconomic status vary by etapa, such that the older etapas often have better conditions than the newer ones. Following invitation by the locals, a nonprofit organization (NPO) was one of the first responders to the refugee crisis that resulted after Hurricane Mitch and it has been on the scene in Nueva Vida since then, fostering development and improvement in the living standards of the people.

After identifying cervical cancer as a preventable problem affecting their patient population, the Nueva Vida Clinic, which is operated by the NPO, implemented free Pap smear screening based on the see-and-treat approach for women between the ages of 18 and 65. The understanding of the NPO was that women in Nueva Vida were aware of cervical cancer screening and Pap smears, however, women were not aware of the frequency of screening needed, the need to follow-up on test results to determine if the Pap smear was normal or abnormal, and the availability of treatment following an abnormal Pap. In addition, there was not an option for treatment at the local clinic at this time. Thus, women who needed treatment following screening at the facility were referred to another facility for treatment. Part of the motivation for the study was that the clinic had new equipment to treat women if they had abnormal pap results. It was understood locally that women knew they were supposed to get Pap smears but would not necessarily get screened due to other competing priorities (such as work, taking care of children, the household, etc.), and those who required treatment after screening were often unable to go to other facilities due to transportation issues and scheduling difficulties. Further, it was thought that women did not follow-up to receive test results or treatment if necessary. The NPO thought it would be helpful to raise awareness of the need to get screened, what the process should be, and the steps to take after screening. 
A partnership was, therefore, formed between two U.S. universities and the NPO to conduct projects for the benefit of the community of Nueva Vida through an interprofessional graduate course. The partnership is an ongoing relationship to investigate the major health needs of the population annually for appropriate program planning of the NPO. To better understand the underlying risk factors for not being screened, health promotoras who were already working in the Nueva Vida community were used to assess the prevalence and reasons for not receiving pap smears in Nueva Vida while simultaneously promoting the new see-and-treat program at the clinic. The promotoras were trained by university partners and local NPO staff on survey administration and how to counsel on obtaining a Pap smear. The survey was designed by the research team with input from the clinic staff. It was translated into Spanish and refined by the promotoras for clarity and culturally appropriate language. While conducting the survey, women were generally receptive despite the sensitive topic, probably due to the presence of the promotoras who were known in the community. The survey was administered anonymously, ensuring that no information that could be used to identify study participants was included.

Though the survey was created to inform the intervention programs of the NPO in Nueva Vida, Nicaragua, collaborators later decided that the findings were worth publishing. Hence, an application for ethical approval was submitted to the Institutional Review Board of one of the U.S. universities, but exempted as secondary data. The nonprofit clinic provided a permission letter in support of the use of the secondary data.

\section{Procedure}

Of the 34 promotoras, 32 received an hour-long training including role-playing and information on completing surveys. Promotoras and researchers went door-to-door, surveying women within the specified age group that were available at the time of visit in each etapa of the community. Promotoras administered the surveys in Spanish. Researchers helped to ensure surveys were collected properly and information regarding the see-and-treat program was given out. The survey was carried out from July 10 to July 17, 2014. Women of all ages that were available and willing to take the survey were included. No ages were excluded because of Nicaragua's high fertility rate and early onset of sexual relationships. Further, lack of sexual activity was provided as a response option for not having a Pap. Data were collected, evaluated, and presented back to the clinic.

Data analysis was completed with IBM SPSS Version 24.0 and Microsoft Excel 2016. Statistics derived include measures of central tendency, frequencies, and proportions. The age of participants was categorized to allow for further analysis as ordinal data. Chi-square tests of independence were conducted between etapa and ever having a Pap smear, etapa and Pap smear results, age group and ever having a Pap smear, and age group and Pap smear results. For the chi-square analysis, data for the surrounding etapas (Trinidad Central, Trinidad Norte, and Cuajachillo) were merged to increase the sample size for that group. A $t$-test was done to compare the difference in mean age group between women who had ever had a Pap smear and those who had never had a Pap smear. Charts were created for visual presentation of results. 


\section{Results}

A total of 1,117 women were surveyed, of which only 1,098 had complete data. Table 1 shows the distribution of women by etapa, with the largest number from Etapa 2 . The women surveyed were aged 14 to 95 years. The mean age was 35.7 years, with a standard deviation of 13.7 years, whereas the median age was 33 years, and the age with the highest frequency was 32 years. Ages exceeding 72.5 years were considered as outliers. Table 1 displays the age distribution, with majority (29.9\%) of the participants aged 21-30 years, though the median age group was 31-40 years.

Table 1. Demographic Distribution of Participants, Pap Smear Utilization Survey, Nueva Vida, Nicaragua, July 2014

\begin{tabular}{lcc}
\hline Characteristic & Number of Participants & Percent $(\%)$ \\
\hline Etapa $(n=1,117)$ & & \\
Etapa 1 & 221 & 19.8 \\
Etapa 2 & 304 & 27.2 \\
Etapa 3 & 171 & 15.3 \\
Etapa 4 & 158 & 14.1 \\
Etapa 5 & 51 & 4.6 \\
Trinidad Norte & 30 & 2.7 \\
Cuajachillo & 90 & 8.1 \\
Trinidad Central & 92 & 8.2 \\
Age group (years; $n=1,108)$ & & \\
$14-20$ & 134 & 12.1 \\
$21-30$ & 331 & 29.9 \\
$31-40$ & 295 & 26.6 \\
$41-50$ & 181 & 16.3 \\
$51-60$ & 104 & 9.4 \\
$61-64$ & 20 & 1.8 \\
65 and above & 43 & 3.9 \\
\hline
\end{tabular}

Overall, 78.4\% of respondents reported ever having had a Pap smear. The mean age for those who had ever had a Pap smear was 35.93 years, while the mean age for those who had never had a Pap smear was 35.14 years. As shown in Figure 1, the Pap smear utilization varied by etapa. Trinidad Central had the highest proportion of women who had ever had a pap smear (97.8\%), while Etapa 4 had the lowest proportion (72.0\%). 
120.0

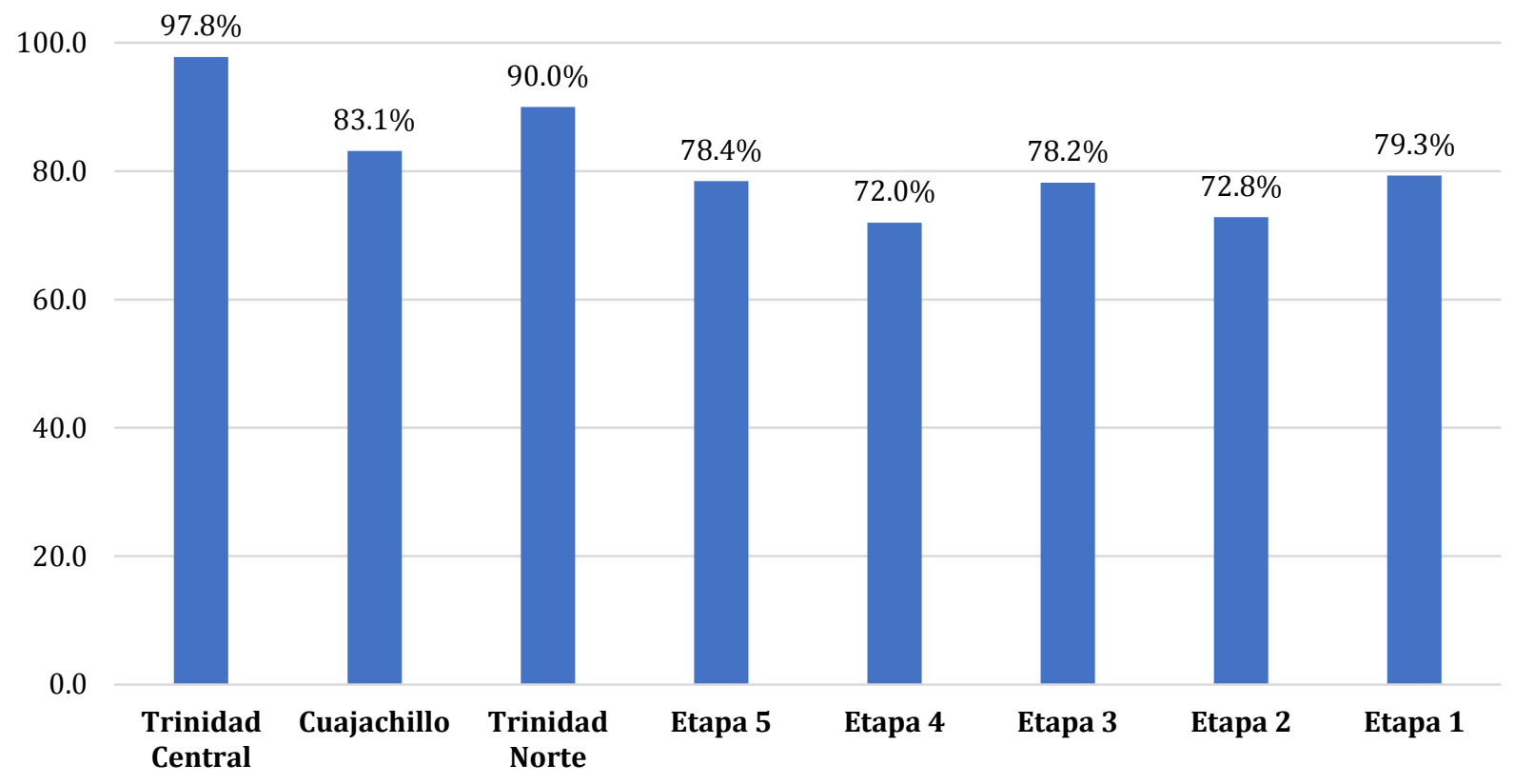

Figure 1. Distribution of Pap Smear Utilization Rates by Etapa, Pap Smear Utilization Survey, Nueva Vida, Nicaragua, July 2014

Pap smear utilization also varied by age category, as seen in Table 2, with women aged 31-40 years having the highest rate (82.9\%) and a slightly lesser rate (81.6\%) in those aged $41-50$ years. Women aged $14-20$ years had the lowest utilization rate (65.9\%) of all age groups.

Out of 861 women who had ever had a Pap smear, 791 disclosed their Pap smear results. The majority (78.9\%) reported a normal result, while $10 \%$ reported an abnormal result and $11.1 \%$ had not received their results. Of the $10 \%$ that received an abnormal Pap smear result, most of them (81\%) received follow-up for their results. Figure 2 displays the number of women reporting Pap smear results by etapa. 


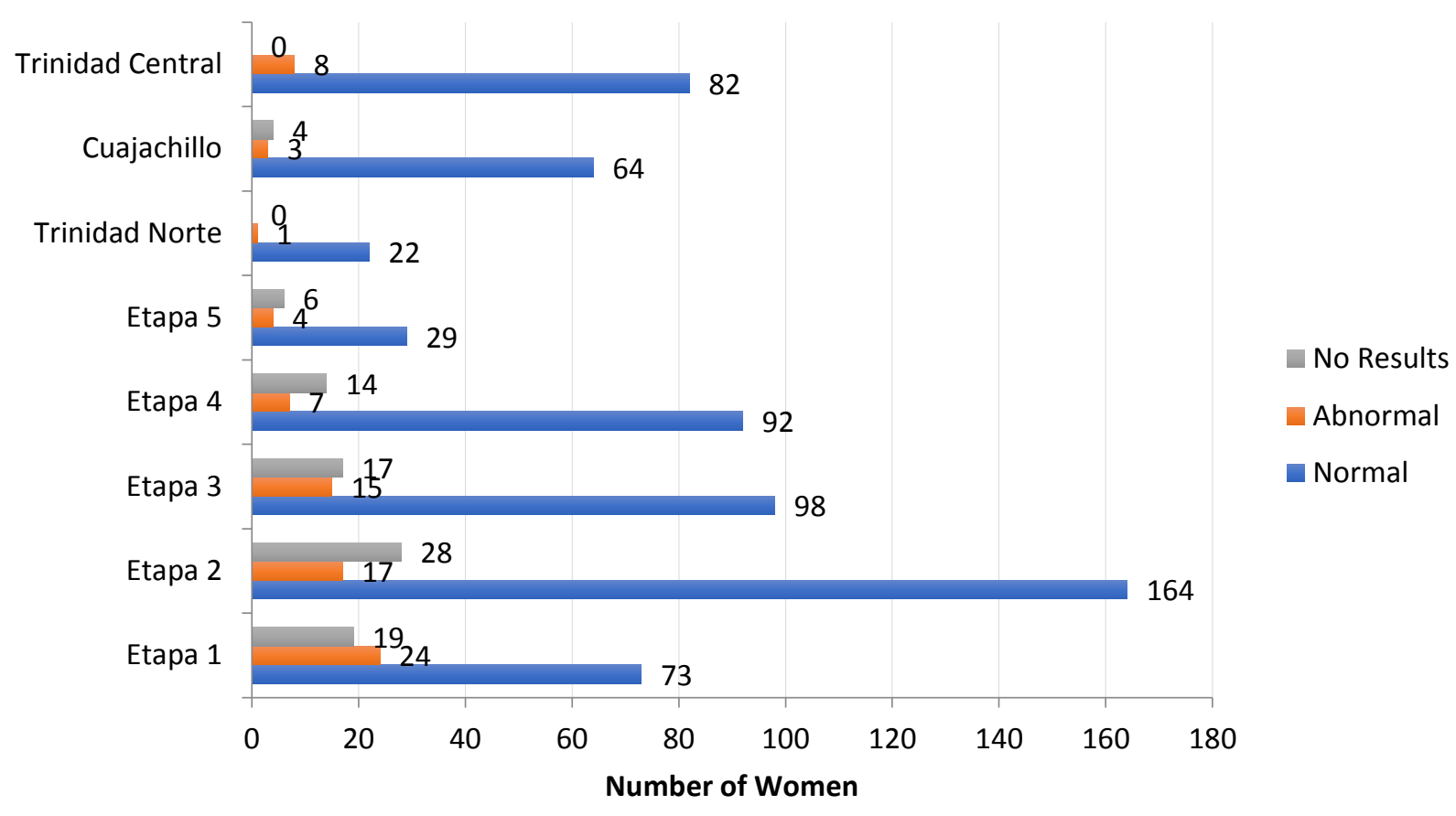

Figure 2. Distribution of Pap Smear Results by Etapa, Pap Smear Utilization Survey, Nueva Vida, Nicaragua, July 2014

Women who had never had a Pap smear gave many reasons why they had not. The most common reasons were "did not want to test," fear, and pain. Figure 3 displays the reasons. If a reason was given five or fewer times, it was included in the "other" category. 


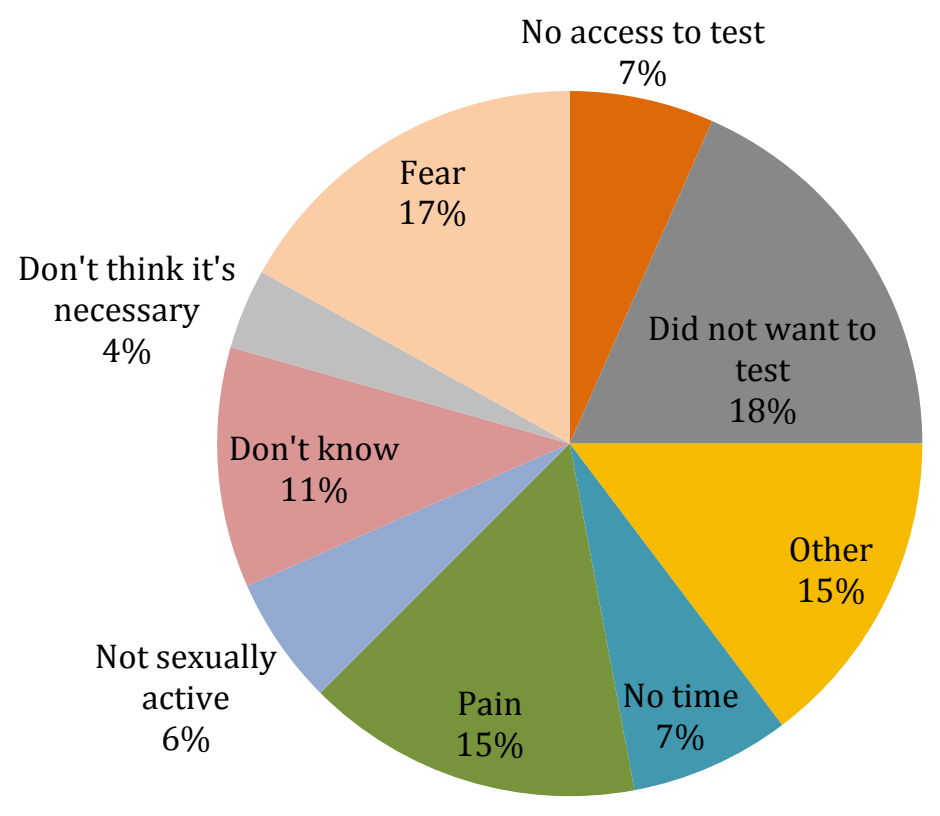

Figure 3. Reasons for Never Having a Pap Smear, Pap Smear Utilization Survey, Nueva Vida, Nicaragua, July 2014

Chi-square analysis shows that for the 1,091 participants that indicated both their age and whether they had ever had a Pap smear, there was statistically significant evidence $\left(\chi^{2}=18.261, p=.006\right.$, $d f=6$ ) that having a Pap smear varied by age group, as seen in Table 2.

Table 2. Distribution of ever having a Pap Smear by Age Group, Pap Smear Utilization Survey, Nueva Vida, Nicaragua, July 2014

\begin{tabular}{lccc}
\hline & \multicolumn{2}{c}{ Ever Had a Pap Smear } & \\
\cline { 2 - 3 } Age Group (years) & No & Yes & 132 \\
\hline $14-20$ & $45(34.1 \%)$ & $87(65.9 \%)$ & 322 \\
$21-30$ & $66(20.5 \%)$ & $256(79.5 \%)$ & 292 \\
$31-40$ & $50(17.1 \%)$ & $242(82.9 \%)$ & 179 \\
$41-50$ & $33(18.4 \%)$ & $146(81.6 \%)$ & 104 \\
$51-60$ & $23(22.1 \%)$ & $81(77.9 \%)$ & 19 \\
$61-64$ & $5(26.3 \%)$ & $14(73.7 \%)$ & 43 \\
65 and above & $12(27.9 \%)$ & $31(72.1 \%)$ & 1,091 \\
Total & $234(21.4 \%)$ & $857(78.6 \%)$ & \\
\hline
\end{tabular}

Note. Pearson $\chi^{2}=18.261, p=.006 ; d f=6$. 
Also, there was statistically significant evidence $\left(\chi^{2}=28.272, p<.001, d f=5\right)$ that there was a difference in proportions of women who ever had a Pap smear by etapa, as seen in Table 3.

Table 3. Distribution of ever having a Pap Smear by Etapa, Pap Smear Utilization Survey, Nueva Vida, Nicaragua, July 2014

\begin{tabular}{lccc}
\hline & \multicolumn{2}{c}{ Ever Had a Pap Smear } & \\
\cline { 2 - 3 } Etapa & No & Yes & Total \\
\hline Etapa 1 & $43(20.7 \%)$ & $165(79.3 \%)$ & 208 \\
Etapa 2 & $83(27.4 \%)$ & $220(72.6 \%)$ & 303 \\
Etapa 3 & $36(21.3 \%)$ & $133(78.7 \%)$ & 169 \\
Etapa 4 & $44(28.0 \%)$ & $113(72.0 \%)$ & 157 \\
Etapa 5 & $11(22.0 \%)$ & $39(78.0 \%)$ & 50 \\
Surrounding etapas & $20(9.5 \%)$ & $191(90.5 \%)$ & 211 \\
Total & $237(21.6 \%)$ & $861(78.4 \%)$ & 1098 \\
\hline
\end{tabular}

Note. Pearson $\chi^{2}=28.272, p<.001, d f=5$.

Furthermore, for the 791 participants who had ever had a Pap smear and indicated both their etapa and their Pap smear results, Table 4 shows statistically significant evidence $\left(\chi^{2}=45.024, p<.001, d f\right.$ $=10$ ) that ever having a Pap smear varied by etapa.

Table 4. Pap Smear Results by Etapa, Pap Smear Utilization Survey, Nueva Vida, Nicaragua, July 2014

\begin{tabular}{lcccc}
\hline & \multicolumn{3}{c}{ Pap Smear Results } & Total \\
\cline { 2 - 4 } Etapa & Normal & Abnormal & Results not given & 117 \\
\hline Etapa 1 & $73(62.4 \%)$ & $24(20.5 \%)$ & $20(17.1 \%)$ & 209 \\
Etapa 2 & $164(78.5 \%)$ & $17(8.1 \%)$ & $28(13.4 \%)$ & 130 \\
Etapa 3 & $98(75.4 \%)$ & $15(11.5 \%)$ & $17(13.1 \%)$ & 113 \\
Etapa 4 & $92(81.4 \%)$ & $7(6.2 \%)$ & $14(12.4 \%)$ & 38 \\
Etapa 5 & $28(73.7 \%)$ & $4(10.5 \%)$ & $6(15.8 \%)$ & 184 \\
Surrounding etapas & $168(91.3 \%)$ & $12(6.5 \%)$ & $4(2.2 \%)$ & 791 \\
Total & 623 & 79 & 89 & 89 \\
\hline
\end{tabular}

Note. Pearson $\chi^{2}=45.024, p<.001, d f=10$.

However, there was no statistically significant evidence $(p=.298)$ that Pap smear result varied by age group. Likewise, a $t$ test showed that there was no statistically significant difference $(p=.431)$ in the mean age of women who had ever had a Pap smear compared with those who had never had a Pap smear.

\section{Discussion}

Barriers to cervical cancer screening have been identified by multiple studies in Latin America and in other countries. These include poor access to quality services, facilities that lack comfort and privacy, high costs, lack of courtesy by providers, poor service delivery, anxiety about the test result, negligence, and fear of cancer (Agurto et al., 2004); low educational level, poor knowledge, lack of 
medical problems, fear, and economic reasons (Claeys et al., 2002); and lack of awareness of cervical cancer and/or Pap smear, and the belief that cervical cancer cannot be prevented (Hyacinth et al., 2012). Other associated factors include being older, reliant on welfare, obese, a current smoker, with history of childhood sexual abuse, or with anxiety symptoms (Olesen et al., 2012).

Similarly, this study noted fear and pain as major reasons for not having Pap smear screening. Contrary to expectations, cost of the procedure was not cited as a barrier to screening. Moreover, the most common reason for not having the Pap smear was "did not want to test," indicating that being aware of the need for a Pap smear does not necessarily translate into utilization of the Pap smear. This response option, though not originally on the questionnaire, turned out to be the response given by majority of the respondents. Reasons for not wanting to test were not disclosed. However, possible factors accounting for this could include that their partners did not permit them to test, or they felt it was not an important test. Prior to this study, the only health facilities that provided Pap smear screening were government clinics, which typically had long wait times and were difficult for the Nueva Vida community to access due to distance and the requirement for a means of identification and an address in the community to be cared for. Previous problematic experiences with the healthcare system may have been a reason for not wanting to test. It is also possible that they did not have any specific reason for not testing and so answered this way. Further research should clarify the reasons for not wanting to test.

The Pap smear utilization rate among the participants (78.4\%) was quite high compared to the utilization reported from eight Latin American and Caribbean countries which was less than 55\% (Soneji \& Fukui, 2013). In addition, only 41\% had received a Pap smear from 1999 to 2002 in Rivas, another city in Nicaragua (Claeys et al., 2002), and a mere 10.2\% had used a Pap smear as reported from a study in Nigeria (Hyacinth et al., 2012). Perhaps accounting for the high Pap smear utilization rate in this survey were the involvement of women of all ages and the way the question was asked, requesting whether they had used a Pap smear in their lifetime, rather than asking if they had used it in the last 3 years, as recommended and asked in other surveys (Claeys et al., 2002). Further, the presence of the non-profit clinic in the community potentially increased access and education via promotoras on the topic compared to surrounding areas. The proximity of the clinic-a resource that is lacking in several other communities in Nicaragua-and the education facilitated by the promotoras may have contributed to an improved health-seeking behavior among the members of the Nueva Vida community (Claeys et al., 2002).

Notably, almost two thirds of women aged 14-20 years had ever had a Pap smear. This is significant because of the early age of onset of sexual intercourse among Nicaraguan women; about half of women in Nicaragua are married and have children before the age of 20 years (Lion, Prata, \& Stewart, 2009). In addition, Nicaragua has one of the highest fertility rates among adolescents in the world, even higher than the rate for sub-Saharan Africa (Lion et al., 2009). If the current utilization rate among women in this age group-who are exposed to several risk factors for cervical cancer-is maintained or increased, it is likely to cause a significant decrease in cervical cancer incidence in the future. Though the American Cancer Society, the American College of Obstetricians and Gynecologists, and the U.S. Preventive Services Task Force (Centers for Disease Control and Prevention, 2012; U.S. Preventive Services Task Force, 2012) recommended against screening women younger than 21 years for cervical cancer, more research studies are needed to ascertain the risk-benefit profile of early cervical cancer screening among women in Nicaragua and similar developing countries. 
Contrary to findings in this study, Hyacinth et al. (2012) reported a statistically significant difference in mean age between women who had a Pap smear compared with those who did not. However, our finding that having a Pap smear varies by age group is in agreement with findings from their study (Hyacinth et al., 2012). Socioeconomic disparities may explain the inequalities in the levels of Pap smear utilization among the etapas, because the older etapas often have better living conditions than the newer ones. Evidence shows that socioeconomic status is a major determinant of Pap smear utilization in Latin America (Soneji \& Fukui, 2013).

Worthy of note is that an important outcome of this research was the collaboration built between researchers, the NPO, and the promotoras. This project has been followed by similar surveying of the community about other health issues annually. The collaboration provides the organization and clinic with data about the community they serve, researchers with public health data, students with hands-on research experience, promotoras with increased engagement with the community, and the community with increased awareness and informed services at the clinic.

This survey was not without limitations. Collecting more information would have allowed further analysis and understanding. If questions included the date of last Pap smear, the type of follow-up for abnormal results, and perhaps where they had the test, such information would have been extremely useful. Further limitations include some data collection problems such as incomplete surveys, multiple answers chosen for one question, and failure to specify the reason for not getting a Pap smear when "other" or "did not want to test" was chosen. In addition, there were no available statistics on the socioeconomic status of the population in each etapa, or in the whole of Nueva Vida. Including questions to determine the demographics of the respondents as well as that of household heads would have given a better understanding of how socioeconomic factors affect the utilization of Pap smears in Nueva Vida.

\section{Conclusion}

Overall, this survey provides significant information for future programming by the NPO, the community, and other partners including the university partners, as well as the larger international NPO community. We recommend an increase in access to Pap smears for the people of Nueva Vida, though this is currently being implemented, and an additional OB/GYN physician has been hired to ensure adequate staffing.

Working with the Nueva Vida Clinic, procedures to increase the reporting of Pap smear results and increase follow-up on abnormal results are currently being developed, this will help to avoid distrust and should encourage more women to test. The clinic started contracting with a private laboratory to avoid any problems with women not receiving their Pap results. The lead promotora follows up with anyone who had an abnormal result and helps them to schedule an appointment. She sends their local promotora out to talk with the woman and bring her in to the clinic. Further investigation into reasons for fear of the test and fear of pain would be helpful in determining how to reduce more barriers to screening.

Furthermore, we recommend provision of the needed see-and-treat methods that would mitigate some of the other issues such as follow-up. Additionally, though the HPV vaccine is currently in limited supply in the area, if barriers to implementation of a HPV vaccination program were addressed systematically, the vaccine could be available in the future. 


\section{References}

Agurto, I., Bishop, A., Sanchez, G., Betancourt, Z., \& Robles, S. (2004). Perceived barriers and benefits to cervical cancer screening in Latin America. Preventive Medicine, 39, 91-98.

Arossi, S., Sankaranarayanan, R., \& Parkin, D. M. (2003). Incidence and mortality of cervical cancer in Latin America. Salud Publica de Mexico, 45, S306-S314.

Bosch, F. X., Robles, C., Diaz, M., Arbyn, M., Baussano, C. C., Ronco, G., ... Cuzick, J. (2016). HPVFASTER: Broadening the scope for prevention of HPV-related cancer. Nature Reviews: Clinical Oncology, 13, 119-132.

Bychkovsky, B. L., Ferreyra, M. E., Strasser-Weippl, K., Herold, C. I., Lopes Jr., G. L, Dizon, D. S., ... Goss, P. E. (2015). Cervical cancer control in Latin America: A call to action. Cancer, 122, 502-514. doi:10.1002/cncr.29813

Centers for Disease Control and Prevention. (2012). Cervical cancer screening guidelines for averagerisk women. Retrieved from https://www.cdc.gov/cancer/cervical/pdf/guidelines.pdf.

Ciapponi, A., Bardach, A., Glujovsky, D., Gibbons, L., \& Picconi, M. A. (2011). Type-specific HPV prevalence in cervical cancer and high-grade lesions in Latin America and the Caribbean: Systematic review and meta-analysis. PLoS One, 6, e25493.

doi:10.1371/journal.pone.0025493

Claeys, P., Gonzalez, C., Gonzalez, M., Page, H., Bello, R. E., \& Temmerman, M. (2002). Determinants of cervical cancer screening in a poor area: Results of a population-based survey in Rivas, Nicaragua. Tropical Medicine and International Health, 7, 935-941.

Colantonio, L., Gomez, J. A., Demarteau, N., Standaert, B., Pichon-Riviere, A., \& Augustovski, A. (2009). Cost-effectiveness analysis of a cervical cancer vaccine in five Latin American countries. Vaccine, 27, 5519-5529. doi:10.1016/j.vaccine.2009.06.097

Decat, P., Nelson, E., De Meyer, S., Jaruseviciene, L., Orozco, M., Segura, Z., ... Degomme, O. (2013). Community embedded reproductive health interventions for adolescents in Latin America: Development and evaluation of a complex multi-centre intervention. BMC Public Health, 13, 1-10. doi:10.1186/1471-2458-13-31

Elliot, P. F., Belinson, S. E., Ottolenghi, E., Smyth, K., \& Belinson, J. L. (2013). Community health workers, social support and cervical cancer screening among high-risk groups in rural Mexico. Journal of Health Care for the Poor and Underserved, 24, 1448-1459.

Franco, E. L., Tsu, V., Herrero, R., Lazcano-Ponce, E., Hildesheim, A., Munoz, N., ... Andrus, J. K. (2008). Integration of human papillomavirus vaccination and cervical cancer screening in Latin America and the Caribbean. Vaccine, 26S, L88-L95. doi:10.1016/j.vaccine.2008.05.026

Gharoro, E. P., \& Ikeanyi, E. N. (2006). An appraisal of the level of awareness and utilization of the Pap smear as a cervical cancer screening test among female health workers in a tertiary health institution. International Journal of Gynecologic Cancer, 16, 1063-1068.

Gilmore, B., \& McAuliffe, E. (2013). Effectiveness of community health workers delivering preventive interventions for maternal and child health in low- and middle-income countries: A systematic review. BMC Public Health, 13, 1-14. doi:10.1186/1471-2458/13/847 
Han, H.-R., Song, Y., Kim, M., Hedlin, H. K., Kim, K., Lee, H. B., \& Roter, D. (2017). Breast and cervical cancer screening literacy among Korean American women: A community health worker-led intervention. American Journal of Public Health, 107, 159-165. doi:10.2105/AJPH.2016.303522

Hindryckx, P., Garcia, A., Claeys, P., Gonzalez, C., Velasquez, R., Bogers, J., ... Cuvelier, C. A. (2006). Prevalence of high risk human papillomavirus types among Nicaraguan women with histological proved pre-neoplastic and neoplastic lesions of the cervix. Sexually Transmitted Infections, 82, 334-336. doi:10.1136/sti.2006.019745

Hyacinth, H. I., Adekeye, O. A., Ibeh, J. N., \& Osoba, T. (2012). Cervical cancer and Pap smear awareness and utilization of Pap smear test among federal civil servants in North Central Nigeria. PLoS One, 7, e46583. doi:10.1371/journal.pone.0046583

Institut Catala d'Oncologia HPV Information Center. (2016). Nicaragua: Human papillomavirus and related cancers [Fact sheet]. Retrieved from http://www.hpvcentre.net/statistics/reports/NIC_FS.pdf

Lion, K. C., Prata, N., \& Stewart C. (2009). Adolescent child-bearing in Nicaragua: A quantitative assessment of associated factors. International Perspectives on Sexual and Reproductive Health, 35, 91-96.

McDermott-Levy, R., \& Weatherbie, K. (2012). Health promotores' perceptions of their communities' health needs, knowledge, and resource needs in rural Nicaragua. Public Health Nursing, 30, 94-105.

Moore, S. P., Forman, D., Pineros, M., Fernadez, S. M., de Oliveira Santos, M., \& Bray, F. (2014). Cancer in indigenous people in Latin America and the Caribbean: A review. Cancer Medicine, 3, 70-80. doi:10.1002/cam4.134

Murillo, R., Molano, M., Martinez, G., Mejia, J.-C., \& Gamboa, O. (2009). HPV prevalence in Colombian women with cervical cancer: Implications for vaccination in a developing country. Infectious Diseases in Obstetrics and Gynecology, 2009, 1-9. doi:10.1155/2009/653598

Murillo, R., Herrero, R., Sierra, M. S., \& Forman, D. (2016). Cervical cancer in Central and South America: Burden of disease and status of disease control. Cancer Epidemiology, 445, S121S130. doi:10.1016/j.canep.2016.07.015

Murillo, R., Almonte, M., Pereira, A., Ferrer, E., Gamboa, O. A., Jeronimo, J., \& Lazcano-Ponce, E. (2008). Cervical cancer screening programs in Latin America and the Caribbean. Vaccine, 26S, L37-L48. doi:10.1016/j.vaccine.2008.06.013

Murillo, R., Luna, J., Gamboa, O., Osorio, E., Bonilla, J., Cendales, R., \& the INC Cervical Cancer Screening Study Group. (2010). Cervical cancer screening with naked-eye visual inspection in Colombia. International Journal of Gynecology and Obstetrics, 109, 230-234. doi:10.1016/j.ijgo.2010.01.019

O’Brien, M. J., Halbert, C. H., Bixby, R., Pimentel, S., \& Shea, J. A. (2010). Community health worker intervention to decrease cervical cancer disparities in Hispanic women. Journal of General Internal Medicine, 25, 1186-1192. doi:10.1007/s11606-010-1434-6

Ogunwale, A. N., Sangi-Haghpeykar, H., Montealegre, J., Cui, Y., Jibaja-Weiss, M., \& Anderson, M. L. (2016). Non-utilization of the Pap test among women with frequent health system contact. Journal of Immigrant Minority Health, 18, 1401-1412. doi:10.1007/s10903-015-0287-9 
Oguro, M., \& Horiuchi, S. (2016). A cross-sectional study of community-based maternal and child health interventions involving women's health volunteer groups in rural Myanmar. Public Health Nursing, 33, 449-459. doi:10.1111/phn.12275

Olesen, S. C., Butterworth, P., Jacomb, P., \& Tait, R. J. (2012). Personal factors influence use of cervical cancer screening services: epidemiological survey and linked administrative data address the limitations of previous research. BMC Health Services Research, 12, 1-9. doi:10.1186/1472-6963-12-34

Pan American Health Organization (PAHO). (2013). Nicaragua cancer profile. Washington, DC: Pan American Health Organization.

Pan American Health Organization (PAHO). (2014). Cervical cancer in the Americas. Retrieved February 6, 2017, from http://www.paho.org/hq/index.php?option=com_docman\&task=doc_view\&gid=17498\&itemid \&Itemid $=270$

Printz, C. (2017). Expert panel issues new global cervical cancer screening. Cancer, 2017, 2387-2389. doi:10.1002/cncr.30811

Saxenian, H. (2007). HPV vaccine adoption in developing countries: Cost and financing issues. New York, NY: International AIDS Vaccine Initiative/Program for Appropriate Technology in Health.

Soneji, S., \& Fukui, N. (2013). Socioeconomic determinants of cervical cancer screening in Latin America. Revista Panamericana de Salud Pública/Pan American Journal of Public Health, 33, 174-182.

U.S. Preventive Services Task Force. (2012). Statement for cervical cancer: Recommendation statement. American Family Physician, 86, 555-559.

World Health Organization (WHO). (2012). Prevention of cervical cancer through screening using visual inspection with acetic acid (VIA) and treatment with cryotherapy: A demonstration project in six African countries. Geneva, Switzerland: Author.

World Health Organization (WHO). (2016). Human papillomavirus (HPV) and cervical cancer. Retrieved from http://www.who.int/mediacentre/factsheets/fs380/en/

World Health Organization (WHO). (2017). Cervical cancer. Retrieved from http://www.who.int/cancer/prevention/diagnosis-screening/cervical-cancer/en/

The Journal of Social, Behavioral, and Health Sciences is an open-access, peer-reviewed, online interdisciplinary journal focusing on research findings that address contemporary national and international issues. Its objectives are to (a) encourage dialogue between scholars and practitioners in the social, behavioral, and health sciences that fosters the integration of research with practice; (b) promote innovative models of interdisciplinary collaboration among the social, behavioral, and health sciences that address complex social problems; and (c) inform the relationship between practice and research in the social, behavioral, and health sciences.

Walden University Publishing: http://www.publishing.waldenu.edu 